\title{
Resilience design: toward a synthesis of cognition, learning, and collaboration for adaptive problem solving in conservation and natural resource stewardship
}

\author{
Charles G. Curtin $^{1,2}$
}

\begin{abstract}
Through the resilience design approach, I propose to extend the resilience paradigm by re-examining the components of adaptive decision-making and governance processes. The approach can be divided into three core components: (1) equity design, i.e., the integration of collaborative approaches to conservation and adaptive governance that generates effective self-organization and emergence in conservation and natural resource stewardship; (2) process design, i.e., the generation of more effective knowledge through strategic development of information inputs; and (3) outcome design, i.e., the pragmatic synthesis of the previous two approaches, generating a framework for developing durable and dynamic conservation and stewardship. The design of processes that incorporate perception and learning is critical to generating durable solutions, especially in developing linkages between wicked social and ecological challenges. Starting from first principles based on human cognition, learning, and collaboration, coupled with nearly two decades of practical experience designing and implementing ecosystem-level conservation and restoration programs, I present how design-based approaches to conservation and stewardship can be achieved. This context is critical in helping practitioners and resources managers undertake more effective policy and practice.
\end{abstract}

Key Words: cognition; collaborative adaptive management; linked social-ecological systems; resilience design; wicked systems

\section{INTRODUCTION}

Despite immense promise and significant levels of adoption, adaptive management (AM) has, for the most part, not delivered the benefits of more sustainable, relevant, and effective conservation and resource management that were anticipated at its inception. The optimism of the early work by C. S. Holling and colleagues in the 1970s (Holling 1978), and reflections on practice nearly two decades later in such works as Lee's (1993) Compass and Gyroscope and Gunderson et al.'s (1995) Barriers and Bridges, among others, have now given way to the realization that AM is relatively simple in theory and considerably more difficult in practice.

The era of management is over, according to one of AM's founders Don Ludwig (2001). Conceding that the complexities involved mean that it is hubris to assume that people can control large, complex systems, he states "...there is ample evidence that systems approaches and management are inappropriate for the complex ("wicked") problems that are most important today." These problems are characterized by "radical uncertainty" and "a plurality of legitimate perspectives," which indicates that approaches that are more dynamic and integrative are needed.

Another of the early proponents of AM, William Clark (2002:1) wrote that the process "...has yet to fulfill its promise in practice." Clark cited the limitations of institutional designs involved in large-scale social-ecological experiments and recognized many challenges to effective implementation, "not the least the complexity of the linked ecological and social systems that adaptive management seeks to address and the high political stakes involved in the outcomes it seeks to influence." (Clark 2002:1).

What the results of many ecosystem-level experiments reveal is the soft underbelly of AM, which, as a paradigm and practical approach does, not go far enough toward establishing effective collaborative practices and place-based approaches as cornerstones of resilience and sustainability. Another one of AM's long-time proponents, Kai Lee, in a recent conversation, referred to much of current AM as "adaptive management lite", in which agencies and organizations go through the motions, but fail to establish and use essential feedback loops and other key elements of effective design (Lee, personal communication). This results in the system lacking the capacity to learn, as illustrated by many of the major examples from vast ecosystem projects such as the Everglades (Light and Adamowsky 2012) and Glen Canyon (Jacobs and Wescoat 2002). AM in current practice often exists as management without the capacity for adaptation. Lee admitted that he no longer has the optimism reflected in his book of 20 years ago (Lee, personal communication). "We are in the weeds" he notes, recognizing that the reality is much more complex and nuanced than originally perceived by the discipline's founders. However, the stakes are higher than ever that we get it right, for the severity of global problems only continues to increase.

So what is missing to make AM more effective and relevant? I argue that AM fails not just because it is intrinsically hard and we frequently lack the political and social will, but also because current approaches do not go far enough in understanding how people conceive of problems, learn from experience, and develop the collaborative processes to develop and sustain solutions.

\section{TOWARD RESILIENCE DESIGN}

A fundamental point, which is rarely recognized, is that the larger implications of resilience science and AM spell the death of conventional planning. If one is to "expect the unexpected," as advocated by resilience science and AM (e.g., Holling 1986) and view management as a series of adaptive experiments (e.g., Lee 1993, Gunderson et al. 1995), then the old strategy of building 
future predictions on past experience is impossible in our rapidly changing world. Further, planning to adapt using a series of overarching principles is not planning at all; it is design. Planning vs. design might just seem like a case of semantics, but the underlying difference is fundamental. The words are often used interchangeably, but the outcomes and processes are profoundly different.

Planning is "the act of formulating a program for a definite course of action," whereas design is "devising for a specific function or end" (http://thefreedictionary.com). Thus, design is a fundamental departure from conventional planning and management. AM is the process of adaptation to change. However, the real durability of solutions lies in not just learning from the past or adapting to the present, but designing for the future. Adaptive responses in and of themselves are intrinsically halfway solutions that do the "wrong thing righter" by attempting to plan rather than design for the future (e.g., Ison and Collins 2008).

The framework for examining the pre-conditions for emergent and resilient policy and process has been termed by myself and colleagues as resilience design. The three fundamental elements of resilience design that set the pre-conditions for lasting approaches to address conservation and natural resource stewardship are: (1) equity design, which is the integration of collaborative approaches and governance to generate effective self-organization and emergence; (2) process design, which is the generation of effective knowledge through development of information inputs; and (3) outcome design, which is a synthesis of the previous two approaches, generating the framework for developing durable yet dynamic approaches to conservation and stewardship. Outcome design is primarily concerned with the practical aspects of sustaining individuals and organizations long enough and at scales large enough to make a fundamental difference.

\section{EQUITY DESIGN}

In equity design, the principal social and ecological barriers to be addressed for solving wicked problems, including those typically encountered in AM, are generating an open and transparent process to reduce social fragmentation and communication breakdowns. At its core, solving complex problems, or at least finding effective compromises, requires eliminating barriers and enhancing connectivity. Key facets of this process are: (1) an understanding of individual and group cognition, or the way we perceive problems and their solutions; (2) the principles of effective collaboration, or the way we collectively solve problems; and how we learn, both individually and collectively; and (3) to develop and sustain the feedback loops for creative and innovative responses to social-ecological challenges.

\section{Cognition}

An understanding of cognition suggests that collaborative, placebased approaches are foundational for sustained, effective conservation and resource stewardship and management (hereafter referred to only as stewardship, in deference to Ludwig's [2001] point that large systems cannot really be "managed"). Our brains contain an abundance of stored neural patterns that created through experience. How we respond to a particular situation is largely determined by which neural pathways, and therefore, which past experiences, are activated (Maturana and Varela 1987, Beratan 2007). These priming effects are a key to unconscious selection processes with all sensory inputs, including verbal and nonverbal human communication, activating particular patterns of neural connections. In essence, people hold in their heads mental maps of how they will respond to a particular situation and they become almost hard-wired to respond in particular ways to new circumstances based on past experience. Focusing events such as stressful or challenging experiences are retained more effectively because stress hormones activated by emotional situations enhance long-term memory and modify responses to change (Cahill and McGaugh 1998). By contrast, in nonstressful situations, repeated exposure over time is needed for new ideas to be learned and consolidated into long-term memory (Beratan 2007). These elements of cognition underscore the intrinsic challenges in overcoming distrust and control issues that are the undoing of so many collaborative ventures, and also why trust-based collaborative approaches are so key to sustained problem solving.

The human mind is essentially a complex adaptive system with hierarchical organization. Properties observed at one functional level, e.g., memories or thoughts, are emergent from lower levels such as neurons that are the building blocks of cognitive architecture. The mind uses a process of differentiation between expected and unexpected, known and unknown, to come up with a solution in response to a given situation if it does not have one already in its memory. Hutchins (1995) noted that culture is an emergent process stemming from the "accumulation of partial solutions to frequently encountered problems." A few simple rules lead to emergent processes of immense complexity, yet by focusing on the component parts, a foundation for decision-making, collective action, and learning emerge. Building collaborative processes builds the cognitive adaptive capacity to respond to change.

As an understanding of the function of the brain reveals, few of our thoughts reach the level of conscious awareness because $98 \%$ of cognition is unconscious (Bargh and Chartrand 1999). We are often unaware of the process of thought and only experience the outcome. This has significant implications in the policy arena because the unconscious processing of the brain often defines a potential set of solutions (Beratan 2007). Often in resource management, decision makers assume they know the problem before they develop a solution, and seldom examine the underlying assumptions or seek alternative explanations or solutions. Effective approaches, then, require conscious cognitive approaches that demand understanding one's own biases and creating a system to adapt and adjust to change with these biases taken into consideration (Senge 1990).

However, the mind does not exist in isolation, being largely a product of its environment and the collective understanding of those around us. Memory and understanding are both an individual and collective process, and we are highly influenced by collective action and interaction (Hutchins 1995). Therefore, cognition is individual and collective, and this broad understanding forms the template through which we experience the world and understand and address challenges. Our cultural environment produces norms and commonly held perceptions that vary through time and across countries, cultures, and 
continents, creating distributed cognition. This is critical in guiding collective action in generating sustainable approaches to environmental challenges. Taken as a whole, the results of studies of individual and distributed cognition indicate that collaboration is essential and results from a few simple factors related to how we collect and assess information. The key question is: how do these cognitive underpinnings play out in conservation and resource management? An examination of the collaboration processes holds some of the answers.

\section{Collaboration}

Effective decision-making, from a cognitive perspective, provides a theoretical foundation for three fundamental premises (Beratan 2007). First, a successful transformation toward AM tends to emerge from informal networks that help facilitate information flows, identify knowledge gaps, and create nodes of expertise (Olsson et al. 2006). Second, joint understanding of process in collectively held conceptual or mechanistic models is essential for developing the common ground necessary to generate effective action in response to change (Curtin 2005, Walker et al. 2006, Karl et al. 2007). Finally, collaborative approaches are relatively slow, time consuming, and expensive, yet the cognitive and social elements of theory and practice demonstrate that they are necessary. There are no shortcuts to effective design and reflective practice.

However, the question of the viability of centralized vs. localized approaches to conservation and stewardship continues to be widely debated, with the arguments largely determined by the assumptions imbedded in how the question is framed. At one extreme, legal scholars such as Coggins (1998) see collaboration as a threat to environmental protection, circumventing federal authority, and leading to devolution of power to local governments or private entities, yet they never address if legal topdown approaches are even successful in the long term. Political scientists such as Layzer (2006) frame the question in terms of national vs. local control. In a critique of Layzer, for example, Crocker (2008), based on first-hand experience in marine policy, uses an example from the fisher's perspective to illustrate how such academic writing about natural resource policy can be compelling and logically consistent while being, at best, ecologically and socially naïve, and at worst, damaging to communities and ecosystems. This is because such approaches do not take into account the social and ecological realities faced by the players in the system, or the collective processes needed to sustain effective resource stewardship. I found similar shortcomings in Layzer's critiques of the rangeland ecosystems, with which I am familiar (e.g., Curtin 2005, 2010). In both cases, the analyses fail to account for the importance of building local capacity; more fundamentally, they do not account for the cognitive underpinnings that suggest the mind's predisposition to collaborative approaches to sustain effective processes. The authors of those critiques miss the emergent outcomes of developing a foundation in local knowledge coupled with science, and greatly simplify complex social interactions. The devil is in the details, and the success or failure of programs often turn on subtle nuances missed by dispassionate, external academic assessment. These academic reviews too often take a Newtonian "clock-work" view of the world that is reductionist and reactive, when in reality, the situations call for responses that are complex and emergent. It is the constraints and opportunites posed by the human brain's architecture that indicate why we must develop policy approaches that entrain adaptive and distributive approaches to environmental problem solving.

The implications of a cognitive perspective is supported by an increasing amount of literature from around the world that illustrates the importance of collaborative approaches to conservation and natural resource stewardship, including from Africa (Western et al. 1994, Child and Lyman 2005), Asia (Leeuwis and Pyburn 2002), Eastern Europe (Gruber 2010), and the United States (Daniels and Walker 2001, Child and Lyman 2005, Tilt et al. 2005, Ballard et al. 2008, Dukes et al. 2011). Elinor Ostrom's (1990) Nobel Prize-winning work on commons theory is one of the most powerful and widely accepted examples of the importance of the emergent outcomes of peoples' interaction with their environment.

\section{Feedback loops}

A key facet to building effective information feedbacks is through different kinds of learning. Learning emerges from the interaction of individuals and organizations and the social and ecological systems within which they are embedded. Individuals and organizations learn from their interactions with each other, but they seldom do so deliberately. Learning is a self-organized process in which the more information that is available, the greater the range of choices for action. However, these choices are constrained by the individuals, organisms, and institutions involved, their cognitive abilities, and their ability to seek the most effective choices from the total range of options.

Chris Argyris and Donald Schön, organizational theorists from business schools at Harvard and MIT, were among the first to propose a typology for understanding different approaches to learning and institutional/organizational design (Argyris and Schön 1978). In single-loop learning, the individual, group, or organization essentially modifies its actions according to differences between obtained and expected outcomes. Here, the decision maker does not seek the best outcome among competing objectives, but instead a satisfactory result for each goal, viewing the goals as isolated or taken one at the time. This leads to shortterm approaches that address the outcome rather than the root of the problem.

The fundamental need to develop new responses, rather than repeat old pathologies, leads to the concept of double-loop learning, in which assessment of the assumptions, policies, or values that led to past actions leads to the development of new approaches (Argyris and Schön 1978). Much of the challenge of adaptive approaches to conservation and policy design lie with moving beyond single-loop learning to building multi-loop frameworks for problem solving. The art is in designing an approach in which alterative frameworks can be safely and effectively examined and developing processes that are "safe-tofail" to create a space for experimentation and learning to occur (Clark et al. 1979).

More recently, there has evolved the concept of transformational or triple-loop learning (Garratt 1986, Swieringa and Wierdma 1992), with related concepts of "learning to learn," extending back to the early 1970s (Michael 1973). The goal is to generate transformative approaches that allow for innovation. Flood and Romm (1996) examine triple-loop approaches through the lens 
of three interconnected questions: Are we doing things right? Are we doing the right things? Is the right approach leading to more effective action? It is transformational by affecting not just our behavior and thinking, but also our identity or umwelt, the worldview through which we see ourselves and the overall context of the challenges we are addressing.

This paradigm is similar to what is called experimental learning (e.g., Armitage et al. 2008) in that it is learning by doing through an iterative cycle involving four stages: concrete experience, reflective observation, abstract conceptualization, and active experimentation. The approach requires developing a reflective process in which the individual's perceptions of the problem are altered through the process. However, in practice, triple-loop learning is often a product of surprise or dramatic events, approaches that result from creative destruction (Schumpeter 1942) in which old approaches are rapidly dispensed with in the face of new realities. This often results in both breakthrough innovation (Mascitelli 2000) and disruptive innovation (Kambil et al. 2000), which are new intellectual directions and fundamentally different pathways toward perceiving the environment and developing potential solutions.

However, learning not only occurs at the level of the individual or society, but also at the level of the organization. In what is called social learning by Armitage et al. (2008), this approach builds on Argyris and Schön's (1978) foundation to incorporate single- and double-loop learning into a foundation that involves knowledge creation coupled with organizational creativity to generate innovation (Morgan 1988, Leeuwis and Pyburn 2002, Wang and Ahmed 2003, Keen et al. 2005). In short, organizational processes should not focus on the static organization entity, but on active processes within and between organizations that are, at their very root, cognitive enterprises (Argyris and Schön 1978). From organizational theory developed by system theorists at Harvard and MIT to the on-the-ground experience of practitioners, successful action ultimately depends on approaches that engage people in an equitable, open, and transparent process. However, without collective goals and common ground, people are prone to succumbing to social fragmentation, resulting in competition and conflict. Effective problem-solving balances short- and long-term interests and power structures. It can be both implicit by using a few assembly rules to develop selforganization, yet also explicit by developing clear goals and guiding principles. The next step is to ensure that the feedback loops are in place that can inform and sustain these dynamic processes because a continual flow of information is what maintains the community's ability to evolve and respond to change.

\section{PROCESS DESIGN}

Process design depends on working across scales of resolution to find the options and leverage points that generate resilience and viable AM. These points of leverage lie at the interface of ecological and social systems, where both risks and opportunities are greatest (Meadows 1999). Finding leverage points requires integrating knowledge types in which the world is perceived at different scales. Refining this knowledge and formally communicating it helps to build the learning loops to critically assess AM and avoid AM "lite". The core tools to accomplish this include setting the context through attaining practical knowledge, setting the scale through monitoring, and refining knowledge through experimental science.

\section{Practical knowledge: setting the context}

In terms of the process, the more complex or "wicked" a problem (e.g., Rittel and Webber 1973), the more informal means (collective or individual-based perceptions) are needed to address it. System theorist Peter Checkland made the distinction between hard and soft systems. Hard systems use formal experimentation and collection of empirical data where possible. The classic example is the 1960s NASA Space Program, in which a few equations, made on the relatively simple computers of the day, sent a rocket around the moon. By contrast, soft systems are much more difficult, usually requiring more descriptive approaches because of their sheer complexity. Even situations as simple and commonplace as basic social interactions are immensely difficult to predict. Informal local knowledge systems are often key to understanding complex systems and can help lead to sufficient understanding to focus more intensive efforts. For example, the rancher-led AM program in the Malpai Borderlands of southern Arizona and New Mexico used ranchers' understanding to focus research methods. In fisheries examples from the Gulf of Maine, local fishers' knowledge is fundamentally changing the understanding of cod stock structure and fisheries management (Curtin 2010).

A foundation for navigating soft systems is local and traditional ecological knowledge, the cultural capital by which societies convert natural capital, resources, and ecological services into economic goods and services. The challenge is to not talk past other groups, but rather to find those places of common ground where different perceptions can come together to generate common points of leverage. However, exploiting leverage points often means having the social capital, long-term context, and ecological understanding that only comes from more formal processes of information gathering. Monitoring can fulfil this role.

\section{Monitoring: setting the scale}

Monitoring of social and ecological variables is commonly perceived as a means of tracking long-term change. However, it has a second, almost more important role of documenting the range of variation within a system. This is the key to establishing the scale of conservation, science, and stewardship. The level of design or scale of action must be larger than the range of variation in the system. All conservation and management is contextual, so understanding the role of variability is crucial for designing effective AM.

In social science literature, as well as in agency and conservation organization handbooks, there are repeated calls for monitoring to document system change. However, all monitoring is not equal, and the process of monitoring itself is rarely evaluated. Funders and agencies seem to take it on faith that monitoring is intrinsically good, whereas very often it is a halfway solution with little or no predictive power. Monitoring is often promoted on the grounds of being relatively inexpensive, but nothing is a bargain unless it yields useful information; science without controls or adequate replication is, in the end, still poor science.

Monitoring can be an important part of effective decision-making and understanding the range of variability in systems. However, 
as commonly practiced, it all too often represents institutionalized single-loop learning, in which people document what they expect to see, as well as a political solution that provides the illusion of action without accompanying insight that might force activity or provide further insight that could challenge existing goals or paradigms. Developing baselines through monitoring is certainly important, and well-designed methods for gathering and archiving information are crucial for ensuring durability and the institutional context for understanding change. However, monitoring is far more effective when it is linked with other knowledge types.

\section{Experimental science: refining knowledge}

At the highest level of research intensity are experimental approaches. These are studies that, by their very nature, can only be conducted on relatively small portions of the landscape. Because of these constraints, experimental science must be used judiciously and is most effective when applied near ecological and social boundaries, both where different systems meet and where dynamics are most likely to be revealed (Curtin 2008). Although experimental approaches are not free of observer bias, welldesigned experimental studies are distinct from other approaches to learning in that they allow an empirical test of assumptions. Perhaps more than any other level of inquiry, well-designed experiments, especially ones that extend over long time periods, have emergent properties that can reveal unexpected or unforeseen results. The challenge then, for researcher and practitioner alike, is to develop science that yields fundamentally new insights, i.e., the triple-loop knowledge that is transformative and essential for effective response to change.

However, two challenges also emerge. First, more precision in science does not necessarily mean more accuracy. There are innumerable cases of highly precise studies that are ultimately irrelevant to conservation because they ask the wrong question or ask the right question at the wrong scale (e.g., Wilson 2006). Second, as with monitoring, research is most effective when conducted over a long enough time span to capture patterns of environmental variation. To do this requires continuity. In experimental research, it is better to document a few simple measures well, rather than a broad range of variables poorly. This means that in large and complex systems, it is important to work on what can be sustained long enough to see longer-term patterns, ideally over at least ten years, while using periodic external review to reassess the process. However, obtaining funding through the existing grant systems often requires that a project grow and evolve to receive further funding. Herein lies another pitfall. The continual need to alter research priorities to meet shifting funding priorities often detracts from core program design, generating short-term benefits at the expense of long-term continuity, especially in large, complex systems that integrate social and ecological variables and where scale-relevant research can take decades. The challenge of sustaining viable research programs is essential for generating effective knowledge and feedbacks in a sustained AM process.

In summary, when seeking leverage points and developing feedback loops, there are no shortcuts for gaining effective knowledge; a combination of approaches is needed. The intersection of local knowledge, monitoring, and experimental science facilitates triple-loop learning by incorporating the dynamic tension between hard-won local knowledge plus the more formal scientific process of monitoring that establish context, and experimental science that tests underlying assumptions.

\section{OUTCOME DESIGN}

With outcome design, the point is to make equity and durable processes a reality. Although Canadian management professor Henry Mintzberg's classic article "Crafting strategy," published in the Harvard Business Review, is devoted to understanding effective business approaches, it has much to teach conservationists and policy designers about how to be effective. Mintzberg states, "In practice, of course, all strategy making walks on two feet, one deliberate, the other emergent." The point is to have a framework in place that maintains the state of the organization while being able to take advantage of opportunities when they arise. However, frameworks need to be deliberately emergent by developing a process to facilitate a more spontaneous but reflective response to change. This is not change for its own sake, but is used to locate what Mintzberg calls the discontinuities, or those moments in time when being aggressively proactive or seeking change really counts.

How does one develop tools to facilitate emergent approaches that are proactive without being destabilizing? A foundation grounded in principles is key. An example of such an approach is the principle-based ethos of the Northwest Atlantic Marine Alliance (NAMA) in the Gulf of Maine. Developed in 1995 through intensive strategy sessions with Visa credit card founder Dee Hock and fishers, conservationists, and marine policy leaders at the invitation of the Conservation Law Foundation, the message used was simple: align diverse interests through basic principles. The vision statement that emerged from these meetings was: "to restore and enhance an enduring northwest Atlantic marine system, which supports a healthy diversity and abundance of marine life and human uses."

However, beyond this general mission statement, NAMA also developed a detailed set of organizational principles. For example, they sought to "vest authority in and make decisions at the most local level that includes all relevant and affected parties." They also developed principles of practice such as to "encourage adaptability, diversity, flexibility, learning, and innovation in all governance processes and practices." These instructions recognize the importance of not dictating results, but rather of developing the preconditions for innovation and emergence. However, there are pitfalls here as well, for the NAMA guidelines have on occasion been found too limiting, placing organizations in an organizational straightjacket (R. Alden, personal communication). In recent years, founding principles have come to represent more of a middle ground between being visionary and prescriptive, with the recognition that there are essentially two kinds of principles: ethical and procedural. For effective resilience design, it is important to incorporate both.

The experience of both marine and terrestrial-based collaboratives (e.g., Curtin 2010) suggests that it is essential to have both a vision statement with clear broad goals as well as a detailed set of principles to make sure that the project or organization holds true to its founding ideals. This is especially important as the leadership changes and the group evolves, with the guiding principles helping to maintain a clear sense of mission 
and purpose while also creating the flexibility to allow organizations to adapt and evolve. This sounds obvious, but it is remarkable how few projects have effective guiding principles.

Effective practice is also as much about pragmatism as idealism, so how are principles made into reality? In attaining durable solutions, one needs to develop the organizational infrastructure to sustain the process. In this regard, funding is a key part of the process of sustaining AM. Funding introduces another scale issue. The problem with most grants and agreements is that they are usually short-term solutions for decades-long problems. It is in the context of this fundamental discontinuity that the greatest threats and opportunities exist. There has been a great deal written about organizational fundraising and the financing of institutions, but almost all of this information is written for the initial startup phase. However, it is in the transition period, from seven to ten years, when a program has been around long enough to be old to funders but not in place long enough to be truly established, when the greatest challenges occur. Sustaining funding needs to be built into an effective AM process.

\section{CLOSING REMARKS}

In summary, an understanding of equity, process, and outcome design strongly suggests that a primarily collaborative approach provides the institutional resilience and durability sufficient to address change. Fundamental elements of success and longevity place emphasis on promoting social learning and knowledge transfer through increased stakeholder involvement (e.g., Shindler and Aldred Cheek 1999, Wondolleck and Yaffee 2000, Carlsson and Berkes 2005, Folke 2006, Pahl-Wostl 2006, Dukes et al. 2011, Karl et al. 2012) and more networked organizational structures (Argyris and Schön 1978, Senge 1990, Folke 2006). The importance of dialog in building resilience and sustainability indicates that collaborative approaches to AM are critical for finding effective and durable solutions to complex problems (Senge 1990, Beratan 2007). Further, the distributive nature of knowledge and effective decision-making illustrates the need for a diversity of people with a range of expertise to address complex problems (March and Simon 1958, Hutchins 1995, Karl et al. 2012).

Although not all collaboration is effective and is often intrinsically difficult, there are no examples of effective conservation or resource stewardship that I can find of sustainable approaches that did not include significant elements of collaborative practice. The approach is not the outcome of fanciful speculation of dogooders or a desire for feel-good approaches. As has been demonstrated here, it is grounded in a diverse body of theory and practice. The power of resilience design lies in collaborative approaches that do not dictate, but rather set the pre-conditions for success, building institutional structures that take an intrinsically long-term view, and matching the scale and resolution of the problem with that of the solution.

Responses to this article can be read online at: http://www.ecologyandsociety.org/issues/responses. php/6247

\section{Acknowledgments:}

This work was influenced by discussions with Kathi Beratan, Herman Karl, Steven Light, Jessica Parker, and Lynn Scarlett. I thank Steve Alexander and Jessica Parker and external reviewers for many improvements to the manuscript.

\section{LITERATURE CITED}

Argyris, C., and D. Schön. 1978. Organizational learning: a theory of action prospective. Addison-Westly, Reading, Pennsylvania, USA.

Armitage, D., M. Marschke, and R. Plummer. 2008. Adaptive comanagement and the paradox of learning. Global Environmental Change 18(1):86-98. http://dx.doi.org/10.1016/j.gloenvcha.2007.07.002

Ballard, H. L., M. E. Fernandez-Gimenez, and V. E. Sturtevant. 2008. Integration of local ecological knowledge and conventional science: a study of seven community-based forestry organization in the USA. Ecology and Society 13(2): 37. [online] URL: http:// www.ecologyandsociety.org/vol13/iss2/art37/.

Bargh, J. A., and T. L. Chartrand. 1999. The unbearable automaticity of being. American Psychologist 54(7):462-479. http://dx.doi.org/10.1037//0003-066X.54.7.462

Beratan, K. K. 2007. A cognition-based view of decision processes in complex social-ecological systems. Ecology and Society 12(1): 27. [online] URL: http://www.ecologyandsociety.org/vol12/iss1/ art27/.

Cahill, L., and J. L. McGaugh. 1998. Modulation of memory storage. Pages 85-90 in L. R. Squire and S. M. Kosslyn, editors. Findings and current opinion in cognitive neuroscience. MIT Press, Cambridge, Massachusetts, USA.

Carlsson, L., and F. Berkes. 2005. Co-management: concepts and methodological implications. Journal of Environmental Management 75(1):65-76. http://dx.doi.org/10.1016/j.jenvman.2004.11.008

Child, B., and M. West Lyman, editors. 2005. Natural resources as community assets: lessons from two continents. Sand County Foundation, Madison, Wisconsin, USA, and Aspen Institute, Aspen, Colorado, USA.

Clark, W. C. 2002. Adaptive management, heal thyself. Environment 44(2):i.

Clark, W. C., D. D. Jones, and C. S. Holling. 1979. Lessons for ecological policy design: a case study of ecosystem management. Ecological Modelling 7(1):1-53. http://dx.doi.org/10.1016/0304-3800 (79)90008-5

Coggins, G. C. 1998. Of californicators, quislings and crazies: some perils of devolved collaboration. Chronicle of Community 2(2):27-33.

Crocker, M. 2008. Sharing the ocean: stories of science, politics, and ownership from America's oldest industry. Northwest Atlantic Marine Alliance, Gloucester, Massachusetts, USA, and Tilbury House Press, Gardiner, Maine, USA.

Curtin, C. G. 2005. Complexity, conservation, and culture in the Mexico/U.S. borderlands. Pages 237-258 in B. Child and M. West Lyman, editors. Natural resources as community assets: lessons 
from two continents. Sand County Foundation, Madison, Wisconsin, USA, and Aspen Institute, Aspen, Colorado, USA.

Curtin, C. G., editor. 2008. Emergent properties of the interplay between climate, fire, and grazing in desert grasslands. Desert plants volume 24. University of Arizona Press, Tucson, Arizona, USA.

Curtin, C. G. 2010. The ecology of place and natural resource management: examples from marine and terrestrial ecosystems. Pages 251-274 in I. Billick and M. V. Price, editors. The ecology of place: contributions of place-based research to ecological understanding. University of Chicago Press, Chicago, Illinois, USA.

Daniels, S. E., and G. B. Walker. 2001. Working through environmental policy conflict: the collaborative learning approach. Praeger, Westport, Connecticut, USA.

Dukes, E. F., K. F. Firehock, and J. E. Birkhoff. 2011. Communitybased collaboration: bridging socio-ecological research and practice. University of Virginia Press, Charlotteville, Virginia, USA.

Flood, R. L., and N. R. A. Romm. 1996. Diversity management: triple loop learning. Wiley, New York, New York, USA.

Folke, C. 2006. Resilience: the emergence of a perspective for social-ecological systems analyses. Global Environmental Change 16(3):253-267. http://dx.doi.org/10.1016/j.gloenvcha.2006.04.002

Garratt, B. 1986. The learning organization. Harper-Collins, London, UK.

Gruber, J. S. 2010. Key principles of community-based natural resource management: a synthesis and interpretation of identified effective approaches for managing the commons. Environmental Management 45(1):52-66. http://dx.doi.org/10.1007/s00267-008-9235y

Gunderson, L. H., C. S. Holling, and S. S. Light, editors. 1995. Barriers and bridges to the renewal of ecosystems and institutions. Columbia University Press, New York, New York, USA.

Holling, C. S., editor. 1978. Adaptive environmental assessment and management. Wiley, Chichester, UK.

Holling, C. S. 1986. The resilience of terrestrial ecosystems: local surprise and global change. Pages 292-317 in W. C. Clark and R. E. Munn, editors. Sustainable development of the biosphere. Cambridge University Press, Cambridge, UK.

Hutchins, E. 1995. Cognition in the wild. MIT Press, Cambridge, Massachusetts, USA.

Ison, R., and K. Collins. 2008. Policy that does the right thing rather than the wrong thing righter. In Analysing collaborative and deliberative forms of governance. Australia National University, Canberra, Australia. [online] URL: http://oro.open.ac. $\underline{\mathrm{uk} / 27355 / 2 / \text { public policy ison.pdf. }}$

Jacobs, J. W., and J. L. Wescoat, Jr. 2002. Managing river resources: lessons from Glen Canyon dam. Environment: Science and Policy for Sustainable Development 44(2):8-19. http://dx.doi. org/10.1080/00139150209605595

Kambil, A., E. D. Eselius, and K. A. Monteiro. 2000. Fast venturing: the quick way to start web businesses. MIT Sloan Management Review 41(4):55-67.
Karl, H. A., L. Scarlett, J. C. Vargas-Moreno, and M. Flaxman, editors. 2012. Restoring lands: coordinating science, politics, and action. Springer, Dordrecht, The Netherlands. http://dx.doi. org/10.1007/978-94-007-2549-2

Karl, H. A., L. E. Susskind, and K. H. Wallace. 2007. A dialogue, not a diatribe: effective integration of science and policy through joint fact finding. Environment: Science and Policy for Sustainable Development 49(1):20-34. http://dx.doi.org/10.3200/ENVT.49.1.20-34

Keen, M., V. A. Brown, and R. Dyball. 2005. Social learning in environmental management: towards a sustainable future. Earthscan, Abingdon, UK.

Layzer, J. A. 2006. The environmental case: translating values into policy. CQ Press, Washington, D.C., USA.

Lee, K. N. 1993. Compass and gyroscope: integrating science and politics for the environment. Island Press, Washington, D.C., USA.

Leeuwis, C., and R. Pyburn. 2002. Social learning in rural resource management. Pages 11-24 in C. Leeuwis and R. Pyburn, editors. Wheelbarrows full of frogs: social learning in rural resource management. Van Gorcum, Assen, The Netherlands.

Light, S. S., and J. Adamowski. 2012. Flow in the Everglades. Pages 261-304 in H. A. Karl, L. Scarlett, J. C. Vargas-Moreno, and M. Flaxman, editors. Restoring lands: coordinating science, politics, and action. Springer, Dordrecht, The Netherlands. http:// dx.doi.org/10.1007/978-94-007-2549-2 13

Ludwig, D. 2001. The era of management is over. Ecosystems 4 (8):758-764. http://dx.doi.org/10.1007/s10021-001-0044-X

March, J. G., and H. A. Simon. 1958. Organizations. Wiley, New York, New York, USA.

Mascitelli, R. 2000. From experience: harnessing tacit knowledge to achieve breakthrough innovation. Journal of Product Innovation Management 17(3):179-193. http://dx.doi. org/10.1111/1540-5885.1730179

Maturana, H. R., and F. J. Varela. 1987. The tree of knowledge: the biological roots of human understanding. New Science Library, Boston, Massachusetts, USA.

Meadows, D. 1999. Leverage points: places to intervene in a system. Sustainability Institute, Hartland, Vermont, USA. [online] URL: http://www.donellameadows.org/wp-content/userfiles/Leverage_Points. pdf.

Michael, D. N. 1973. On learning to plan and planning to learn. Jossey-Bass, San Francisco, California, USA.

Morgan, G. 1988. Riding the waves of change: developing managerial competencies for a turbulent world. Jossey-Bass, San Franciso, California, USA.

Olsson, P., L. H. Gunderson, S. R. Carpenter, P. Ryan, L. Lebel, C. Folke, and C. S. Holling. 2006. Shooting the rapids: navigating transitions to adaptive governance of social-ecological systems. Ecology and Society 11(1): 18. [online] URL: http://www. ecologyandsociety.org/vol11/iss1/art18/.

Ostrom, E. 1990. Governing the commons: the evolution of institutions for collective action. Cambridge University Press, Cambridge, UK. http://dx.doi.org/10.1017/CBO9780511807763 
Pahl-Wostl, C. 2006. The importance of social learning in restoring the multifunctionality of rivers and floodplains. Ecology and Society 11(1): 10. [online] URL: http://www.ecologyandsociety. org/vol11/iss1/art10/.

Rittel, H. W. J., and M. M. Webber. 1973. Dilemmas in a general theory of planning. Policy Sciences 4(2):155-169. http://dx.doi. org/10.1007/BF01405730

Schumpeter, J. A. 1942. Capitalism, socialism and democracy. Harper, New York, New York, USA. http://dx.doi. org/10.4324/9780203202050

Senge, P. M. 1990. The fifth discipline. Doubleday/Currency, New York, New York, USA.

Shindler, B., and K. Aldred Cheek. 1999. Integrating citizens in adaptive management: a propositional analysis. Conservation Ecology 3(1): 9. [online] URL: http://www.ecologyandsociety.org/ vol3/iss1/art9.

Swieringa, J., and A. Wierdsma. 1992. Becoming a learning organization: beyond the learning curve. Addison-Wesley, London, UK.

Tilt, W., C. Conley, M. James, J. Lynn, T. Munoz-Erickson, and P. Warren. 2005. Creating successful collaborations: lessons from the West. Pages 1-21 in C. van Riper and M. K. Sogge, editors. The Colorado Plateau III: integrating research and resources management for effective conservation. University of Arizona Press, Tucson, Arizona, USA.

Walker, B. H., L. H. Gunderson, A. P. Kinzig, C. Folke, and L. Schultz. 2006. A handful of heuristics and some propositions for understanding resilience in social-ecological systems. Ecology and Society 11(1): 13. [online] URL: http://www.ecologyandsociety. org/vol11/iss1/art13/.

Wang, C. L., and P. K. Ahmed. 2003. Organisational learning: a critical review. Learning Organization 10(1):8-17. http://dx.doi. org/10.1108/09696470310457469

Western, D., R. M. Wright, and S. C. Strum, editors. 1994. Natural connections: perspectives in community-based conservation. Island Press, Washington, D.C., USA.

Wilson, J. A. 2006. Matching social and ecological systems in complex ocean fisheries. Ecology and Society 11(1): 9. [online] http://www.ecologyandsociety.org/vol11/iss1/art9/.

Wondolleck, J. M., and S. L. Yaffee. 2000. Making collaboration work: lessons from innovation in natural resource management. Island Press, Washington, D.C., USA. 